\title{
Genetics of human heterotaxias
}

\author{
Lirong Zhu ${ }^{1}$, John W Belmont*,1 and Stephanie M Ware ${ }^{2}$
}

\author{
${ }^{1}$ Department of Molecular and Human Genetics, Baylor College of Medicine, Houston, TX, USA; ${ }^{2}$ Department of \\ Pediatrics, Cincinnati Children's Hospital Medical Center and University of Cincinnati College of Medicine, Cincinnati, \\ $\mathrm{OH}, \mathrm{USA}$
}

The past decade has seen remarkable advances in defining the molecular mechanisms underlying formation of the embryonic left right (LR) axis. This information is slowly transforming our understanding of human birth defects that are caused by disturbed LR axis patterning. Reversals, isomerisms, or segmental discordances of thoraco-abdominal organ position, that is, classic heterotaxy, clearly indicate embryonic disruption of normal LR patterning. Other isolated birth defects, particularly cardiovascular malformations, may be caused by deficiencies in the same pathways. Here, we review the distinctive clinical features of human heterotaxias and try to summarize the known connections between them and the corresponding developmental pathways.

European Journal of Human Genetics (2006) 14, 17-25. doi:10.1038/sj.ejhg.5201506; published online 26 October 2005

Keywords: heterotaxy; left-right patterning; cardiovascular malformations; birth defects

\section{Introduction}

Heterotaxy is a class of congenital disorders resulting from failure to establish normal left-right (L-R) asymmetry during embryonic development. The resulting defects are characterized by segmental discordances along the $\mathrm{L}-\mathrm{R}$ axis. Given recent research implicating $\mathrm{L}-\mathrm{R}$ patterning genes in isolated congenital heart defects, biliary tract anomalies, cystic renal disease, and malrotation of the intestine, ${ }^{1}$ one may hypothesize that defects in embryonic $\mathrm{L}-\mathrm{R}$ patterning have an even broader role in causing human congenital malformations.

Model organism studies have shown that the functions of $>80$ genes are required for normal asymmetric L-R organ development. While some of these genes probably have a conserved function in humans, mutations in relatively few genes have been identified in patients with heterotaxy. These include ZIC $3,{ }^{2} L E F T Y A,{ }^{3}{ }^{3}$ CRYPTIC, ${ }^{4}$ and $A C V R 2 B .{ }^{5}$ Single cases with mutations in CRELD $1^{6}$ and

\footnotetext{
*Correspondence: Dr JW Belmont, Department of Molecular and Human Genetics, Baylor College of Medicine, One Baylor Plaza, Room T826, Houston, TX 77030, USA. Tel: + 1713798 4634; Fax: + 1713798 8704; E-mail: jbelmont@bcm.tmc.edu

Received 27 June 2005; revised 25 August 2005; accepted 14 September 2005; published online 26 October 2005
}

$N K X 2.5^{7}$ have been reported and so the role of these genes needs further investigation. The mechanistic heterogeneity of human heterotaxy is further illustrated by the various inheritance patterns observed. For example, a few heterotaxy patients carrying balanced reciprocal translocations or inversion have been observed, ${ }^{8,9}$ including a recent report of a balanced $(\mathrm{X} ; 21)$ translocation involving a nonmutated but potentially inactivated ZIC3 gene region. ${ }^{10}$ This review will summarize current clinical and basic research approaches to these interesting disorders.

The clinical phenotype of heterotaxy: terminology and associated malformations

Traditionally, the nomenclature describing the anatomic defects in heterotaxy has been complex, with both syndromic and anatomic designations (see box for definition of terms). There is no consensus with regard to the formal definition of heterotaxy. In its broadest sense, it encompasses any abnormality of organ situs and thus includes situs inversus totalis and potentially a number of associated disorders of ciliary function. However, many use heterotaxy interchangeably with situs ambiguus, a more restricted anatomic designation. To date, the most com- 
Table 1 Congenital anomalies associated with hetero$\operatorname{taxy}^{\mathrm{a}}$

\begin{tabular}{|c|c|}
\hline Cardiovascular & $\begin{array}{l}\text { Atrioventricular discordance } \\
\text { Atrial isomerism } \\
\text { Double outlet right ventricle } \\
\text { Pulmonary stenosis or atresia } \\
\text { Transposition of the great arteries } \\
\text { Single ventricle } \\
\text { Left ventricular outflow tract } \\
\text { obstruction } \\
\text { Septal defects } \\
\text { Total/partial anomalous venous } \\
\text { return } \\
\text { Interrupted IVC } \\
\text { Bilateral SVC } \\
\text { Conduction system abnormalities }\end{array}$ \\
\hline Gastrointestinal & $\begin{array}{l}\text { Extrahepatic biliary atresia } \\
\text { Intestinal malrotation } \\
\text { Omphalocoele } \\
\text { Duodenal atresia/obstruction } \\
\text { Tracheoesophageal fistula } \\
\text { Annular pancreas } \\
\text { Microgastria } \\
\text { Midline liver } \\
\text { Right-sided stomach }\end{array}$ \\
\hline Pulmonary & $\begin{array}{l}\text { Hyparterial or eparterial bronchi } \\
\text { Impaired mucociliary clearance in } \\
\text { patients with ciliary defects }\end{array}$ \\
\hline $\begin{array}{l}\text { Central nervous } \\
\text { system }\end{array}$ & Neural tube defects \\
\hline Genitourinary/anal & $\begin{array}{l}\text { Imperforate anus } \\
\text { Sacral dysplasia } \\
\text { Renal dysplasia } \\
\text { Horseshoe kidney } \\
\text { Fused adrenal glands } \\
\text { Bifid or septate uterus and vagina }\end{array}$ \\
\hline $\begin{array}{l}\text { Musculoskeletal } \\
\text { Immune } \\
\text { ENT }\end{array}$ & $\begin{array}{l}\text { Vertebral and rib anomalies } \\
\text { Asplenia or polysplenia } \\
\text { Cleft palate }\end{array}$ \\
\hline
\end{tabular}

${ }^{a}$ Noncomprehensive list of anomalies. More extensive information on phenotypic presentation is available. ${ }^{11-15,19,79,80}$ prehensive reports on heterotaxy are autopsy series in which analysis of situs of all organs has been performed. ${ }^{11-14}$ In contrast, clinical literature is dominated by case reports rather than comprehensive series, and the reported congenital anomalies seen in association with heterotaxy are vast (see Table 1). Any internal organ that is asymmetrically positioned can be abnormal in individuals with heterotaxy. In addition, midline defects occur in approximately $40 \%$ of patients. ${ }^{15}$ In clinical practice, it is often difficult or impractical, because of unstable critical illness in the newborn infant, to obtain complete information on positioning of all organs. The wide phenotypic spectrum seen in heterotaxy, in combination with the lack of formal clinical guidelines for the evaluation and management of patients, has made the identification of patterns of laterality defects more difficult, complicated the recruitment of patients for research studies, and potentially obscured genotype-phenotype correlations (Box 1).

\section{Epidemiology and inheritance}

Situs inversus is estimated to occur in 1 in 8000-25000 individuals. The majority of cases are the result of abnormal cilia function or absent cilia and are grouped together as primary ciliary dyskinesia (PCD) disorders, itself a genetically heterogeneous group. Situs ambiguus occurs in only a small number of patients with PCD. Abnormal ciliary function is associated with a wide variety of human diseases including recurrent sinusitis, rhinitis, and bronchitis (immotile cilia syndrome), infertility, hydrocephalus, anosmia, and retinitis pigmentosa. ${ }^{16,17}$ The majority of these PCD disorders have an autosomal recessive inheritance pattern. In addition, defects in cilia structure or formation have been identified in cystic kidney disease, both autosomal dominant and autosomal recessive,

\section{Box 1}

\begin{tabular}{|c|c|}
\hline Situs solitus & The normal arrangement of thoracic and visceral anatomy \\
\hline Heterotaxy & Any form of abnormal arrangement of thoracic and visceral situs; any deviation from situs solitus \\
\hline Situs inversus (totalis) & Complete mirror image arrangement of all internal organs \\
\hline Situs ambiguus & $\begin{array}{l}\text { Abnormal arrangement of internal organs with discordance of thoracic and visceral anatomy; usually } \\
\text { characterized by congenital anomalies }\end{array}$ \\
\hline Left isomerism & $\begin{array}{l}\text { A subtype of situs ambiguous characterized by bilateral left sidedness including polysplenia, bilateral } \\
\text { bilobed lungs, and cardiovascular malformations }\end{array}$ \\
\hline Right isomerism & $\begin{array}{l}\text { A subtype of situs ambiguus characterized by bilateral right sidedness including asplenia, bilateral } \\
\text { trilobed lungs, and cardiovascular malformations }\end{array}$ \\
\hline Asplenia & No spleen \\
\hline Polysplenia & Abnormal formation of splenic tissue including a single spleen with multiple septae or multiple splenules \\
\hline Asplenia syndrome & See right isomerism \\
\hline Polysplenia syndrome & See left isomerism \\
\hline Ivemark's syndrome & $\begin{array}{l}\text { Initial cases described by Ivemark had asplenia and cardiovascular malformations; subsequently } \\
\text { generalized to refer to asplenia or polysplenia cases }\end{array}$ \\
\hline Laterality defect & $\begin{array}{l}\text { Any deviation from situs solitus; also includes the failure to generate asymmetry (e.g. midline liver, } \\
\text { persistence of bilateral superior vena cava) }\end{array}$ \\
\hline Dextrocardia & $\begin{array}{l}\text { Right-sided heart position within the chest rather than in its normal left-sided location; the apex (tip) of } \\
\text { the heart points to the right rather than to the left }\end{array}$ \\
\hline
\end{tabular}


nephronophthisis, and in some forms of Bardet-Biedl syndrome (BBS). However, not all ciliary abnormalities result in laterality defects and most forms of cystic kidney disease are not associated with heterotaxy.

'Classic' situs ambiguus, in which a characteristic cardiovascular malformation is identified in conjunction with visceral situs anomalies, comprises approximately $3 \%$ of congenital heart defect cases and has an estimated prevalence of 1 in 10000 live births. ${ }^{18}$ Familial clustering of situs ambiguus, with pedigrees suggestive of either autosomal dominant or recessive inheritance, has been identified. X-linked heterotaxy is caused by mutations or deletions of the zinc-finger transcription factor $Z I C 3 .{ }^{2}$ Most cases of situs ambiguus are single occurrences in a pedigree and it has previously been assumed that Mendelian inheritance is rare. However, careful phenotypic characterization of family members in these pedigrees has identified isolated cardiac defects, isolated neural tube defects, or abnormal vasculature in 'unaffected' individuals. ${ }^{19}$ Approximately $10 \%$ of infants with heterotaxy have a family history of a close relative with congenital heart defects (JW Belmont, unpublished). As the genes associated with situs ambiguus are identified, mutations are increasingly identified in patients with 'sporadic' heart defects. For example, CRYPTIC and ZIC3 mutations have been independently identified in patients with heterotaxy and also in patients with isolated cardiac malformations such as transposition of the great arteries. ${ }^{20-22}$

Laterality defects have also been associated with environmental exposures. A recent review summarizes known drug or chemical exposures that may cause $\mathrm{L}-\mathrm{R}$ phenotypes in animal models. ${ }^{23}$ Data from the BaltimoreWashington Infant Study, a population-based study of cardiovascular malformations from 1981 to 1989, indicate that maternal diabetes and first trimester cocaine use are associated with heterotaxy, as is monozygotic twinning. ${ }^{24}$ In the same study, family history of a congenital heart defect was significantly associated with heterotaxy (odds ratio $5.1 ; 95 \%$ CI 2.0-12.9) highlighting the genetic component. Furthermore, isolated dextrocardia showed a strong association with family history of congenital heart disease as well as family history of extracardiac anomalies. This finding again illustrates the milder spectrum of abnormalities encompassed by laterality disorders.

To summarize, situs inversus is a well-defined and readily identifiable phenotype that is mainly caused by ciliary abnormalities and inherited in an autosomal recessive fashion. In contrast, situs ambiguus is, perhaps appropriately, much more ambiguous. It is not yet clear what percentage of isolated cardiac defects are mechanistically related to early $\mathrm{L}-\mathrm{R}$ patterning abnormalities. Similarly, a subset of isolated extracardiac anomalies such as intestinal malrotation may represent laterality disorders. The true incidence of human $\mathrm{L}-\mathrm{R}$ patterning defects is not yet known and further definition of the molecular basis may identify a higher incidence than has currently been appreciated by focusing on 'classic' forms of the disorder. The genetics of situs ambiguus are characterized by locus and allelic heterogeneity, reduced penetrance, variable expression, probable gene-environment interactions, and occurrence in conjunction with chromosomal disorders or multisystem syndromes. Phenocopies due to teratogenic exposures are strongly suspected.

\section{Left-right asymmetry in embryonic development}

The vertebrate body plan is established during early embryonic development by formation of three embryonic axes: the anterior-posterior (A-P) axis, dorsal-ventral (D$\mathrm{V})$ axis, and $\mathrm{L}-\mathrm{R}$ axis. The $\mathrm{L}-\mathrm{R}$ axis arises last and reversal of $\mathrm{L}-\mathrm{R}$ asymmetry relative to the existing $\mathrm{A}-\mathrm{P}$ and $\mathrm{D}-\mathrm{V}$ axes results in situs inversus, while complete failure to break bilateral symmetry or maintain asymmetric gene expression causes isomerisms. ${ }^{25}$ Numerous genes have been found to play a role in $\mathrm{L}-\mathrm{R}$ specification and formation in Xenopus, chick, zebrafish, and mouse. Conserved pathways of asymmetric gene expression result in a cascade of lateralized signaling, which are then elaborated into morphological asymmetry. This asymmetric gene expression occurs well before the first morphological sign of L-R asymmetry, the rightward looping of the heart tube on embryonic day 23 (six- to eight-somite stage). ${ }^{26}$ There are at least four major linked processes involved in establishment of the $\mathrm{L}-\mathrm{R}$ axis. The first is a mechanism to break the early bilateral symmetry of the embryo. The second is the cascade that transduces an initial subtle and transient asymmetry to stabilize side-specific gene expression in larger regions of the embryo. The third is to restrict side-specific gene expression via the physical and molecular functions of a midline barrier. Finally, regional molecular asymmetry is converted into asymmetric organogenesis via differential control of cell proliferation, migration, and/or cell death. ${ }^{25,27}$

How and where the early bilateral symmetry of the vertebrate embryo is first broken is still not known with certainty. Recent studies have provided insight into the mechanism contributing to the early assignment of the $\mathrm{L}-\mathrm{R}$ axis using animal models (reviewed by $\mathrm{M}$ Levin ${ }^{23}$ ). In the mouse, the node is the site of the earliest known molecular asymmetry and plays a crucial role in the generation of correct L-R asymmetry. There are two populations of monocilia found at the endodermally derived ventral node cells in gastrulation stage embryos. The centrally located monocilia contain the motor protein Left right dynein (Lrd) and are motile, producing laminar leftward flow of the extraembryonic fluid surrounding the node, called 'nodal flow'. The peripherally located monocilia lack lrd and are immotile. ${ }^{28}$ The $L r d$ gene encodes an outer arm axonemal (ciliary) dynein. In the absence of Lrd function 
(as in inversus viscerum, iv, mouse), node monocilia are completely paralyzed, nodal flow is absent, and $\mathrm{L}-\mathrm{R}$ determination is randomized. ${ }^{29-31} \mathrm{KIF}^{2} \mathrm{~A}^{-/-}, \mathrm{KIF}^{-/-}$, and $\mathrm{Orpk}^{-1-}$ (Polaris) mice have complete absence of node monocilia and display randomization of cardiac looping. ${ }^{32-35}$ In the situs inversus mutant, inv, the nodal cilia are motile but only produce very weak leftward nodal flow. ${ }^{31}$ Based on early observations, it was proposed that morphogens are released into the perinodal fluid, enriched on the left side of the node by leftward flow created by the beating action of node monocilia, and thus trigger the $\mathrm{L}-\mathrm{R}$ determination events. ${ }^{31,35}$ This hypothesis is further supported by evidence that reversal of intrinsic nodal flow results in complete reversal of situs in wild-type embryos, and that artificial flow is able to direct the situs of iv/iv mouse embryos with immotile cilia. ${ }^{36-38}$ However, the morphogens transported by leftward nodal flow have remained unknown. A potentially breakthrough discovery has recently identified membrane-sheathed nodal vesicular parcels (NVPs) at the mouse node. The launching of NVPs appears to be the result of FGFtriggered surface accumulation of cargo morphogens. NVPs are transported leftward by nodal flow, carry Sonic hedgehog (shh) and retinoic acid (RA), and eventually fragment close to the left wall of the ventral node. ${ }^{39}$

Both the central and peripheral monocilia contain Polycystin-2, ${ }^{28}$ a calcium-permeable ion channel. Muta-

Figure 1 (a) Early bilateral symmetry breaking at the node leading to $L-R$ patterning in the mouse embryo. There are two populations of monocilia among the cells of the ventral node. The centrally located motile monocilia express both polycystin- 2 and Ird. The peripheral immotile monocilia contain only polycystin-2. FGF signaling triggers the release of NVPs that carry shh and RA. The NVPs are transported leftward by the nodal flow and finally fragment close to the left wall of the node. This results in an increase in cytoplasmic $\mathrm{Ca}^{2+}$ concentration. In chick, transient elevation of extracellular $\mathrm{Ca}^{2+}$ leads to an increased activation of Notch signaling. The relationship between $\mathrm{Ca}^{2+}$ and Notch signaling is still unclear in the mouse embryo. Activation of the Notch signaling pathway is crucial for the asymmetrical expression of Nodal in the left perinodal region. (b) Sequential transfer of $L-R$ information during mouse embryonic development. Perinodal expression of Nodal is required for the expression of Nodal in the left LPM. Nodal can activate Lefty-1 (human LEFTYA or EBAF), Lefty-2, Pitx2, and its own expression in the left LPM. Nodal signals via the type I TGF- $\beta$ receptors $A L K 4$ and $A L K 7$ in the presence of EGF-CFC coreceptors, Cripto or Cryptic (human CRYPTIC). The type II receptors ActRIIA and ActRIIB (human ACVR2B) phosphorylate Smad2,3 which can then bind Smad4. This complex translocates to the nucleus where it interacts with the FoxH1/FAST transcription activator. The midline functions as both a molecular and a physical barrier to prevent the expression of left-side-specific genes in the right LPM. Lefty-1 is expressed in the left border of the midline. Lefty- 1 and Lefty-2 both inhibit Nodal activation. Pitx2 is a downstream target of Nodal and relays $\mathrm{L}-\mathrm{R}$ patterning information for organogenesis. Zic3 (human ZIC3) acts upstream of Nodal in the L-R axis pathway, although it is not known whether this effect is direct or indirect. How mutations in CRELD1 and NKX2.5 might cause heterotaxy is unknown since they are not thought to play a direct role in $L-R$ patterning or in the transfer of $L-R$ axis information during organogenesis. tions in Polycystin-2 result in an autosomal dominant polycystic kidney disease in humans and $\mathrm{L}-\mathrm{R}$ patterning defects in mice. ${ }^{40}$ Immotile peripheral monocilia have been proposed as sensors for the nodal flow created by the motile central node monocilia. Mechanical deformation of these cilia may initiate the left-specific signaling cascades resulting in an increase in $\mathrm{Ca}^{2+}$ concentration on the left periphery of the node. ${ }^{28}$ Much of our understanding of mechanosensory cilia comes from the studies of the cilia developed on kidney epithelial cells lining the tubules. Mechanical bending of cilia in cultured kidney epithelial cells results in an increased $\mathrm{Ca}^{2+}$ influx, and this effect is abolished if the function of Polycystin-1 or Polycystin-2 is blocked. ${ }^{41}$ However, laterality defects are not found in the Polycystin-1-deficient mice, ${ }^{42,43}$ and to our knowledge, the

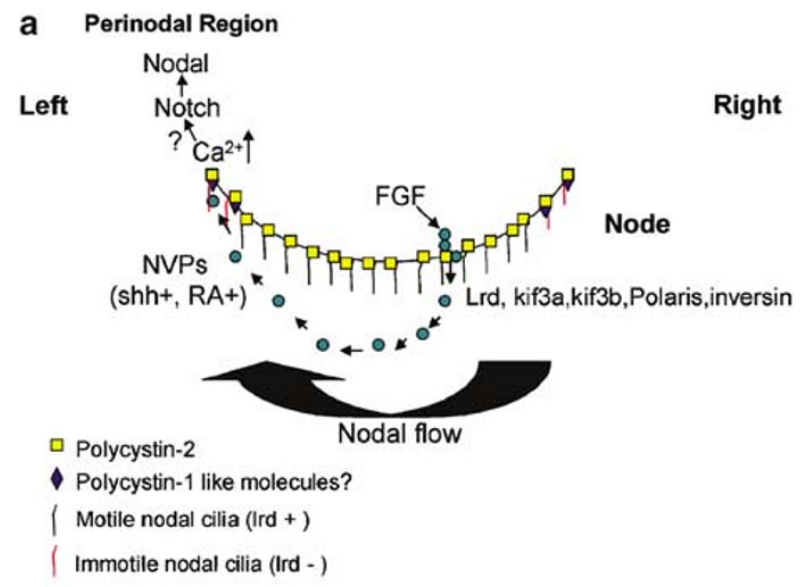

b

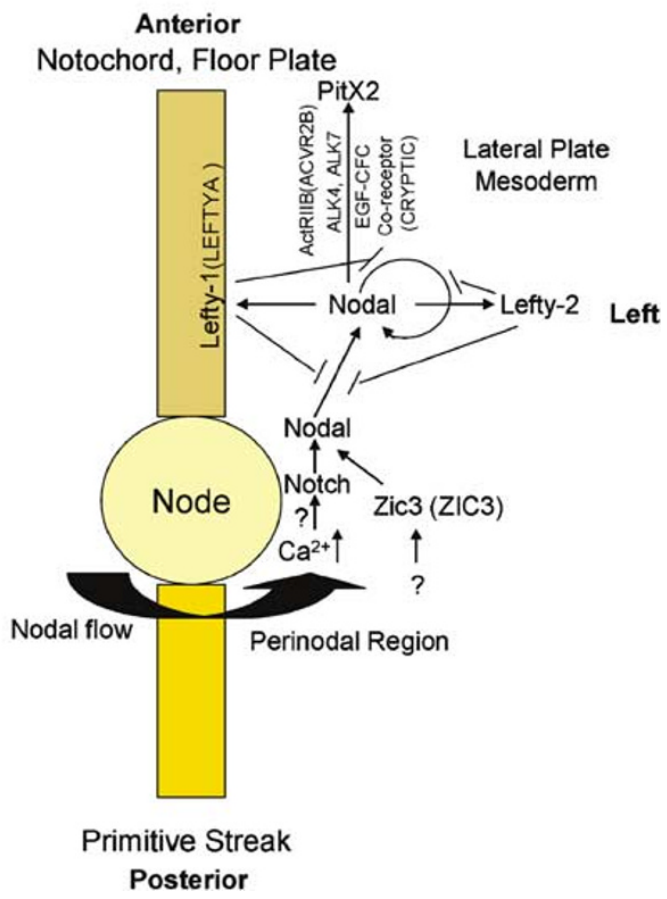


existence of Polysystin-1 in node monocilia has not been reported. It will be interesting to determine whether a Polycystin-1-like molecule ${ }^{43}$ can associate with Polycystin2 and mediate mechano- or chemosensation in the node. Tanaka and colleagues recently found that SU5402 (a specific inhibitor of FGF receptor tyrosine kinase) suppressed NVP secretion and a downstream rise in $\mathrm{Ca}^{2+}$, although the critical parameters of nodal fluid flow in embryos remained unchanged. Moreover, in iv/iv mouse embryos (central monocilia paralyzed), NVPs are still released but do not flow to the left, and cytoplasmic $\mathrm{Ca}^{2+}$ is elevated bilaterally in perinodal cells. ${ }^{39}$ These findings suggest that extracellular signaling molecules carried by leftward nodal flow must play an important role in L-R patterning (Figure 1a).

The conserved expression of a dynein gene that is implicated in ciliary function in mouse, chick, Xenopus, and zebrafish implies that a common ciliary mechanism may underlie the establishment of $\mathrm{L}-\mathrm{R}$ axis in all vertebrates. $^{44,45}$ Very recent data from zebrafish provide strong experimental evidence in support of the "node flow hypothesis' in vertebrate embryos other than the mouse. ${ }^{37,46}$ However, the initiating event of L-R asymmetry remains to be determined. Genes and proteins with an asymmetric distribution of activity prior to node formation have been discovered in Xenopus, chick, and zebrafish, but not in mouse. There is evidence that intercellular communications via gap junctions are required for proper $\mathrm{L}-\mathrm{R}$ patterning in both chick and Xenopus, prior to the asymmetric gene expression at the node. ${ }^{47,48}$ Asymmetrical localization of maternal $\mathrm{H}^{+} / \mathrm{K}^{+}$-ATPase mRNA during the first two cell divisions in Xenopus is later found to be required for $\mathrm{L}-\mathrm{R}$ asymmetry determination. ${ }^{49}$ Asymmetric serotonergic signaling occurs in Xenopus embryos by the four-cell stage as well as in early chick embryos before the cilia appear. ${ }^{50}$ In addition, Syndecan-2, a transmembrane proteoglycan, is asymmetrically phosphorylated prior to cilia formation at the node and mediates $\mathrm{L}-\mathrm{R}$ patterning of the migrating mesoderm in a non-autonomous manner. ${ }^{51,52}$ Recent findings in zebrafish uncover a very early role of $\mathrm{H}^{+} / \mathrm{K}^{+}$-ATPase activity during $\mathrm{L}-\mathrm{R}$ patterning depending on post-translational differences. ${ }^{46}$

In the mouse, the first asymmetrically expressed gene is Nodal. It is initially expressed symmetrically in the perinodal region and subsequently restricted to the left side of the node between four- and five-somite stages. ${ }^{53}$ Nodal expression around the node is mediated by the activity of the Notch pathway in the mouse, chick, and zebrafish embryos. ${ }^{46,54-56}$ In the chick embryo, there is evidence that the asymmetric activation of Notch results from a transient accumulation of extracellular $\mathrm{Ca}^{2+}$, which in turn requires asymmetric $\mathrm{H}^{+} / \mathrm{K}^{+}$-ATPase activity. ${ }^{56}$ Recent data from zebrafish confirm that Notch signaling acts downstream of $\mathrm{H}^{+} / \mathrm{K}^{+}$-ATPase in the cascade. Downregulation of $\mathrm{H}^{+} / \mathrm{K}^{+}$-ATPase or Notch results in no change in lrd expression, cilia distribution or size, or fluid flow in Kupffer's vesicle (the 'organizer' in zebrafish), however. ${ }^{46}$ The role of $\mathrm{H}^{+} / \mathrm{K}^{+}$-ATPase during early murine $\mathrm{L}-\mathrm{R}$ patterning, and whether Notch activity acts as a sensor for the intracellular increase of $\mathrm{Ca}^{2+}$ on the left periphery of the node, still needs to be determined. Transgenic studies in mice have shown that nodal expression around the node is required for its own expression in the left lateral plate mesoderm (LPM). ${ }^{57}$ In the presence of Nodal coreceptors of the EGF-CFC family (human CRYPTIC, mouse Cripto and Cryptic, zebrafish One-eye pinhead), Nodal signals via the type I TGF- $\beta$ receptors ALK4 or ALK7 in association with either ActRIIA or ActRIIB (human ACVR2A or ACVR2B, respectively) type II receptors to activate Smad2 (and presumably Smad3), Smad4, and FoxH1 (formerly known as FAST) transcription factors. ${ }^{58}$ Findings from the mouse Cryptic and zebrafish Oep mutants suggest that the signaling pathway mediated by Nodal and EGF-CFC activities is essential for transfer of $\mathrm{L}-\mathrm{R}$ positional information from the node to the LPM. ${ }^{59}$ The expression of Nodal in the left LPM is necessary for the establishment of proper directional asymmetry in all vertebrates studied to date. ${ }^{60}$ Nodal signaling in the left LPM is temporally and spatially restricted by Lefty-1 (human LEFTYA) and Lefty-2 by blocking the function of EGF-CFC coreceptors. ${ }^{61,62}$ Lefty-1 and Lefty-2, in turn, are regulated by Nodal activity. ${ }^{63,64}$ In the mouse, Lefty-1 expression in the embryonic midline, including the notochord and the prospective floorplate of the neural tube, is controlled by shh and RA. ${ }^{65}$ The ventral side of the notochord contains monociliated cells, ${ }^{66}$ which presumably contribute to a structural barrier function. Asymmetric Nodal signaling activates Pitx2 in the left LPM via the Smad-FoxH1 pathway $^{67,68}$ (Figure 1b).

The Pitx2 gene is a bicoid-homeodomain transcription factor implicated in the control of L-R asymmetry during organogenesis, including cardiac morphogenesis, gut looping as well as lung development. ${ }^{69}$ Pitx2 is also suggested to be involved in the common outflow tract development via interaction with neural crest cells under the control of Wnt/ $\beta$-catenin signaling pathway. ${ }^{70}$ However, little is known about the downstream targets of Pitx2 in organogenesis. An in vitro study shows that Pitx2 regulates $A N F$ and PLOD1 gene expression in the presence of $\mathrm{Nkx} 2.5 .^{71}$ Overall, the relay of L-R asymmetry cues from the LPM to organ primordia is largely unknown although experiments in zebrafish indicate an important role for asymmetric migration of LPM epithelial cells. ${ }^{72}$ Numerous signaling pathways must be involved and function as a network during asymmetric organogenesis.

In vertebrates, in contrast to the asymmetric position of internal organs and vessels, the musculoskeletal and dermal outer layers of the body wall are symmetric, which arises from the synchronized segmentation of the paraxial mesoderm into aligned pairs of somites along the A-P axis. 
This process is controlled by the activities of Notch, FGF, Wnt, and RA signaling pathways. How do the same signaling pathways convey both symmetric and asymmetric information for the formation of somites and $\mathrm{L}-\mathrm{R}$ axis? Recent studies in zebrafish, chick, and mouse demonstrate that RA signaling buffers the effect of the L-R laterality information and controls the bilateral symmetry of somite formation. ${ }^{46,73,74}$ Whether this RA pathway plays a role in maintenance of symmetry in other tissues remains to be determined.

\section{The clinical evaluation of heterotaxy}

Despite the difficulties presented by the broad phenotypic variability seen in laterality disorders, the approach to a patient with 'classic' heterotaxy is relatively straightforward. A critical first step is to identify the full phenotypic spectrum of abnormalities in the proband and to determine whether it is a case of situs inversus or situs ambiguus. In addition to being essential for patient management, this information is critical for identification of the possible underlying genetic etiology. Patients with situs inversus should have evaluation of ciliary function. Stigmata of BBS, including obesity, retinitis pigmentosa, postaxial polydactyly, and developmental delay, should be evaluated. Although situs inversus is infrequently reported in BBS, it occurs at a significantly higher rate than in the general population. ${ }^{75}$ BBS2 and BBS8 have both been reported in association with situs inversus, but five of eight known BBS genes encode basal body or cilia proteins, implying a potential for laterality defects. ${ }^{76}$ Infantile nephronophthisis (NPHP2), an autosomal recessive cystic kidney disease caused by mutations in INVERSIN, is associated with situs inversus. ${ }^{77}$ Lacking evidence of cystic kidneys or stigmata of BBS, a patient with situs inversus is classified as having PCD and therefore and should be followed by a pulmonologist or allergist/immunologist as needed.

Patients with situs ambiguus require an extensive diagnostic evaluation directed toward defining the anatomy and preventing potential complications. Although the evaluation must be tailored to the presenting complications of the patient, echocardiogram and/or cardiac MRI, abdominal and renal ultrasound, and vertebral X-rays should be performed. The spleen should be evaluated by ultrasound and a peripheral blood smear performed to document the presence or absence of Howell-Jolly bodies, red blood cell inclusions indicative of abnormal spleen function. Functional asplenia requires antibiotic prophylaxis and pneumococcal vaccination. Consideration should be given to barium swallow study to exclude malrotation, CNS imaging, and hepatobiliary scintigraphy.

A three-generation pedigree is an essential component of the evaluation. For PCD disorders, information should be obtained regarding family history of infertility, respiratory distress in the immediate neonatal period, hydrocephalus, bronchiectasis, sinusitis, or chronic otitis. For situs ambiguus, any family history of congenital anomaly is potentially contributory. Furthermore, mouse models suggest that increased pregnancy loss may be associated with mutations in genes responsible for $\mathrm{L}-\mathrm{R}$ patterning.

The large number of syndromes, which have associated laterality defects, is beyond the scope of this review and recent reviews summarize these associations. ${ }^{78,79}$ Nevertheless, it is worth highlighting some of the more common associations. Among aneuploidies, both trisomy 13 and trisomy 18 can have congenital anomalies, which overlap with situs ambiguus and can potentially complicate prenatal counseling if amniocentesis is not performed. Microdeletion 22q11.2 can be associated with laterality defects. Recent analyses of patients with mutations in ZIC3 indicate that probands were given diagnoses of VATER association and a tentative diagnosis of Alagille syndrome prior to molecular identification of the etiology of their congenital anomalies. ${ }^{22}$ It is likely that a number of complex malformation syndromes result from early developmental patterning defects in which laterality can be disrupted.

\section{Prenatal evaluation}

Heterotaxy cases are being identified with increased frequency on prenatal ultrasound, likely reflecting increased technological sophistication. ${ }^{80,81}$ Fetal echocardiography has allowed for more detailed definition of the cardiac anatomy and allows for expectant management. Early fetal heart block is commonly associated with left isomerism. ${ }^{82-85}$ In the absence of a syndromic diagnosis, the prognosis of the fetus is largely based on the cardiac anatomy and/or the presence of biliary atresia. Biliary cystic malformations can be identified prenatally and, although not specific for biliary atresia, are highly suspicious when identified in conjunction with other laterality defects. Genetic counseling in prenatal cases is complex. In addition to discussion of the anatomic defects and their prognosis and management, counseling sessions should also include discussion of both syndromic and nonsyndromic possibilities and an explanation of inheritance patterns.

\section{Identified genetic causes and molecular diagnostics} The molecular players in the determination of $\mathrm{L}-\mathrm{R}$ asymmetry are being elucidated at a rapid pace. For situs inversus, knowledge about the function and assembly of cilia is providing increasing insight into the pathological spectrum of a number of human diseases. As additional information is learned about the assembly, maintenance, 
and function of node monocilia, candidate genes for situs inversus will be identified. For PCD disorders, mutation analysis of axonemal dynein genes $D N A H 5^{86-88}$ and $D N A I 1^{89,90}$ is available on a research basis. Currently, clinical testing is available for a common mutation in $B B S 1$; other BBS testing is available on a research basis. NPHP-2 testing is also available on a research basis.

There are more than 80 genes associated with laterality defects in animal models. Delineation of the pathways of asymmetric gene expression has provided excellent candidate genes for human mutation screening. However, the reduced penetrance and phenotypic variability seen in these conditions are confounding factors. A molecular understanding of the relationship between the development of situs inversus and situs ambiguus is important, as is the identification of the pathways required for triggering asymmetric organ growth downstream of the initial $\mathrm{L}-\mathrm{R}$ pathway. Current clinically available testing includes analysis of six genes with published associations with situs ambiguus in humans: ZIC3, ACVR2B, LEFTYA (EBAF), CRYPTIC, CRELD1, and NKX2.5. LEFTYA (EBAF) and $A C V R 2 B$ are the homologues of murine Lefty-1 and $A c v r 2 b$, respectively. ${ }^{3,5}$ CRYPTIC belongs to the Nodal coreceptors of the EGF-CFC family. ${ }^{4}$ These three genes are essential for $\mathrm{L}-\mathrm{R}$ patterning in animal models (see Figure 1). The murine homologue of ZIC3 acts upstream of Nodal in the $\mathrm{L}-\mathrm{R}$ pathway ${ }^{91}$ although its function is not yet known. CRELD1 is an adhesion molecule implicated in the pathogenesis of atrioventricular septal defects (with or without heterotaxy). ${ }^{6}$ Mutations in the transcription factor Nkx2.5 cause various congenital heart defects and atrioventricular block. ${ }^{92}$ The functions of these two genes during $\mathrm{L}-\mathrm{R}$ patterning remain to be determined. In addition to clinically available testing, a candidate gene approach informed from animal models is being utilized in research testing.

\section{References}

1 Maclean K, Dunwoodie SL: Breaking symmetry: a clinical overview of left-right patterning. Clin Genet 2004; 65: 441-457.

2 Gebbia M, Ferrero GB, Pilia G et al: X-linked situs abnormalities result from mutations in ZIC3. Nat Genet 1997; 17: 305-308.

3 Kosaki K, Bassi MT, Kosaki R et al: Characterization and mutation analysis of human LEFTY A and LEFTY B, homologues of murine genes implicated in left-right axis development. Am J Hum Genet 1999; 64: 712-721.

4 Bamford RN, Roessler E, Burdine RD et al: Loss-of-function mutations in the EGF-CFC gene CFC1 are associated with human left-right laterality defects. Nat Genet 2000; 26: 365-369.

5 Kosaki R, Gebbia M, Kosaki K et al: Left-right axis malformations associated with mutations in ACVR2B, the gene for human activin receptor type IIB. Am J Med Genet 1999; 82: 70-76.

6 Robinson SW, Morris CD, Goldmuntz E et al: Missense mutations in CRELD1 are associated with cardiac atrioventricular septal defects. Am J Hum Genet 2003; 72: 1047-1052.

7 Watanabe Y, Benson DW, Yano S, Akagi T, Yoshino M, Murray JC: Two novel frameshift mutations in NKX2.5 result in novel features including visceral inversus and sinus venosus type ASD. J Med Genet 2002; 39: 807-811.

8 Iida A, Emi M, Matsuoka R et al: Identification of a gene disrupted by inv(11)(q13.5;q25) in a patient with left-right axis malformation. Hum Genet 2000; 106: 277-287.

9 Peeters H, Debeer P, Groenen P et al: Recurrent involvement of chromosomal region 6q21 in heterotaxy. Am J Med Genet 2001; 103: $44-47$

10 Fritz B, Kunz J, Knudsen GP et al: Situs ambiguus in a female fetus with balanced $(\mathrm{X} ; 21)$ translocation - evidence for functional nullisomy of the ZIC3 gene? Eur J Hum Genet 2005; 13: $34-40$.

11 Peoples WM, Moller JH, Edwards JE: Polysplenia: a review of 146 cases. Pediatr Cardiol 1983; 4: 129-137.

12 Phoon CK, Neill CA: Asplenia syndrome: insight into embryology through an analysis of cardiac and extracardiac anomalies. Am J Cardiol 1994; 73: 581-587.

13 Uemura H, Ho SY, Devine WA, Anderson RH: Analysis of visceral heterotaxy according to splenic status, appendage morphology, or both. Am J Cardiol 1995; 76: 846-849.

14 Van Praagh S, Geva T, Friedberg DZ et al: Aortic outflow obstruction in visceral heterotaxy: a study based on twenty postmortem cases. Am Heart J 1997; 133: 558-569.

15 Ticho BS, Goldstein AM, Van Praagh R: Extracardiac anomalies in the heterotaxy syndromes with focus on anomalies of midlineassociated structures. Am J Cardiol 2000; 85: 729-734.

16 Afzelius BA: Cilia-related diseases. J Pathol 2004; 204: 470-477.

17 Pan J, Wang Q, Snell WJ: Cilium-generated signaling and ciliarelated disorders. Lab Invest 2005; 85: 452-463.

18 Lin AE, Ticho BS, Houde K, Westgate MN, Holmes LB: Heterotaxy: associated conditions and hospital-based prevalence in newborns. Genet Med 2000; 2: 157-172.

19 Morelli SH, Young L, Reid B, Ruttenberg H, Bamshad MJ: Clinical analysis of families with heart, midline, and laterality defects. Am J Med Genet 2001; 101: 388-392.

20 Goldmuntz E, Bamford R, Karkera JD, dela Cruz J, Roessler E, Muenke M: CFC1 mutations in patients with transposition of the great arteries and double-outlet right ventricle. Am J Hum Genet 2002; 70: 776-780.

21 Megarbane A, Salem N, Stephan E et al: X-linked transposition of the great arteries and incomplete penetrance among males with a nonsense mutation in ZIC3. Eur J Hum Genet 2000; 8: 704-708.

22 Ware SM, Peng J, Zhu L et al: Identification and functional analysis of ZIC3 mutations in heterotaxy and related congenital heart defects. Am J Hum Genet 2004; 74: 93-105.

23 Levin M: Left-right asymmetry in embryonic development: a comprehensive review. Mech Dev 2005; 122: 3-25.

24 Kuehl KS, Loffredo C: Risk factors for heart disease associated with abnormal sidedness. Teratology 2002; 66: 242-248.

25 Capdevila J, Vogan KJ, Tabin CJ, Izpisua Belmonte JC: Mechanisms of left-right determination in vertebrates. Cell 2000; 101: $9-21$.

26 Belmont JW, Mohapatra B, Towbin JA, Ware SM: Molecular genetics of heterotaxy syndromes. Curr Opin Cardiol 2004; 19: 216-220.

27 Raya A, Belmonte JC: Sequential transfer of left-right information during vertebrate embryo development. Curr Opin Genet Dev 2004; 14: 575-581.

28 McGrath J, Somlo S, Makova S, Tian X, Brueckner M: Two populations of node monocilia initiate left-right asymmetry in the mouse. Cell 2003; 114: 61-73.

29 Supp DM, Witte DP, Potter SS, Brueckner M: Mutation of an axonemal dynein affects left-right asymmetry in inversus viscerum mice. Nature 1997; 389: 963-966.

30 Supp DM, Brueckner M, Kuehn MR et al: Targeted deletion of the ATP binding domain of left-right dynein confirms its role in specifying development of left-right asymmetries. Development 1999; 126: $5495-5504$. 
31 Okada Y, Nonaka S, Tanaka Y, Saijoh Y, Hamada H, Hirokawa N: Abnormal nodal flow precedes situs inversus in iv and inv mice. Mol Cell 1999; 4: 459-468.

32 Taulman PD, Haycraft CJ, Balkovetz DF, Yoder BK: Polaris, a protein involved in left-right axis patterning, localizes to basal bodies and cilia. Mol Biol Cell 2001; 12: 589-599.

33 Marszalek JR, Ruiz-Lozano P, Roberts E, Chien KR, Goldstein LS: Situs inversus and embryonic ciliary morphogenesis defects in mouse mutants lacking the KIF3A subunit of kinesin-II. Proc Natl Acad Sci USA 1999; 96: 5043-5048.

34 Takeda S, Yonekawa Y, Tanaka Y, Okada Y, Nonaka S, Hirokawa N: Left-right asymmetry and kinesin superfamily protein KIF3A: new insights in determination of laterality and mesoderm induction by kif3A-/- mice analysis. J Cell Biol 1999; 145: $825-836$.

35 Nonaka S, Tanaka Y, Okada Y et al: Randomization of left-right asymmetry due to loss of nodal cilia generating leftward flow of extraembryonic fluid in mice lacking KIF3B motor protein. Cell 1998; 95: 829-837.

36 Nonaka S, Shiratori H, Saijoh Y, Hamada H: Determination of left-right patterning of the mouse embryo by artificial nodal flow. Nature 2002; 418: 96-99.

37 Kramer-Zucker AG, Olale F, Haycraft CJ, Yoder BK, Schier AF, Drummond IA: Cilia-driven fluid flow in the zebrafish pronephros, brain and Kupffer's vesicle is required for normal organogenesis. Development 2005; 132: 1907-1921.

38 Cartwright JH, Piro O, Tuval I: Fluid-dynamical basis of the embryonic development of left-right asymmetry in vertebrates. Proc Natl Acad Sci USA 2004; 101: 7234-7239.

39 Tanaka Y, Okada Y, Hirokawa N: FGF-induced vesicular release of Sonic hedgehog and retinoic acid in leftward nodal flow is critical for left-right determination. Nature 2005; 435: 172-177.

40 Pennekamp P, Karcher C, Fischer A et al: The ion channel polycystin-2 is required for left-right axis determination in mice. Curr Biol 2002; 12: 938-943.

41 Nauli SM, Alenghat FJ, Luo Y et al: Polycystins 1 and 2 mediate mechanosensation in the primary cilium of kidney cells. Nat Genet 2003; 33: 129-137.

$42 \mathrm{Lu} \mathrm{W}$, Peissel B, Babakhanlou $\mathrm{H}$ et al: Perinatal lethality with kidney and pancreas defects in mice with a targetted Pkd1 mutation. Nat Genet 1997; 17: 179-181.

43 Nauli SM, Zhou J: Polycystins and mechanosensation in renal and nodal cilia. BioEssays 2004; 26: 844-856.

44 Essner JJ, Vogan KJ, Wagner MK, Tabin CJ, Yost HJ, Brueckner M: Conserved function for embryonic nodal cilia. Nature 2002; 418: $37-38$

45 Essner JJ, Amack JD, Nyholm MK, Harris EB, Yost HJ: Kupffer's vesicle is a ciliated organ of asymmetry in the zebrafish embryo that initiates left-right development of the brain, heart and gut. Development 2005; 132: 1247-1260.

46 Kawakami Y, Raya A, Raya RM, Rodriguez-Esteban C, Belmonte JC: Retinoic acid signalling links left-right asymmetric patterning and bilaterally symmetric somitogenesis in the zebrafish embryo. Nature 2005; 435: 165-171.

47 Levin M, Mercola M: Gap junctions are involved in the early generation of left-right asymmetry. Dev Biol 1998; 203: 90-105.

48 Levin M, Mercola M: Gap junction-mediated transfer of left-right patterning signals in the early chick blastoderm is upstream of Shh asymmetry in the node. Development 1999; 126: $4703-4714$.

49 Levin M, Thorlin T, Robinson KR, Nogi T, Mercola M: Asymmetries in $\mathrm{H}+/ \mathrm{K}+-\mathrm{ATPase}$ and cell membrane potentials comprise a very early step in left-right patterning. Cell 2002; 111: 77-89.

50 Fukumoto T, Kema IP, Levin M: Serotonin signaling is a very early step in patterning of the left-right axis in chick and frog embryos. Curr Biol 2005; 15: 794-803.

51 Kramer KL, Barnette JE, Yost HJ: PKCgamma regulates syndecan-2 inside-out signaling during Xenopus left-right development. Cell 2002; 111: 981-990.
52 Kramer KL, Yost HJ: Ectodermal syndecan-2 mediates left-right axis formation in migrating mesoderm as a cell-nonautonomous Vg1 cofactor. Dev Cell 2002; 2: 115-124.

53 Collignon J, Varlet I, Robertson EJ: Relationship between asymmetric nodal expression and the direction of embryonic turning. Nature 1996; 381: 155-158.

54 Raya A, Kawakami Y, Rodriguez-Esteban C et al: Notch activity induces Nodal expression and mediates the establishment of left-right asymmetry in vertebrate embryos. Genes Dev 2003; 17: $1213-1218$.

55 Krebs LT, Iwai N, Nonaka S et al: Notch signaling regulates leftright asymmetry determination by inducing Nodal expression. Genes Dev 2003; 17: 1207-1212.

56 Raya A, Kawakami Y, Rodriguez-Esteban C et al: Notch activity acts as a sensor for extracellular calcium during vertebrate leftright determination. Nature 2004; 427: 121-128.

57 Saijoh Y, Oki S, Ohishi S, Hamada H: Left-right patterning of the mouse lateral plate requires nodal produced in the node. Dev Biol 2003; 256: 160-172.

58 Whitman M: Nodal signaling in early vertebrate embryos: themes and variations. Dev Cell 2001; 1: 605-617.

59 Yan YT, Gritsman K, Ding J et al: Conserved requirement for EGFCFC genes in vertebrate left-right axis formation. Genes Dev 1999; 13: 2527-2537.

60 Schier AF: Nodal signaling in vertebrate development. Annu Rev Cell Dev Biol 2003; 19: 589-621.

61 Chen C, Shen MM: Two modes by which Lefty proteins inhibit nodal signaling. Curr Biol 2004; 14: 618-624.

62 Cheng SK, Olale F, Brivanlou AH, Schier AF: Lefty blocks a subset of TGFbeta signals by antagonizing EGF-CFC coreceptors. PLoS Biol 2004; 2: E30.

63 Meno C, Gritsman K, Ohishi S et al: Mouse Lefty2 and zebrafish antivin are feedback inhibitors of nodal signaling during vertebrate gastrulation. Mol Cell 1999; 4: 287-298.

64 Yamamoto M, Mine N, Mochida K et al: Nodal signaling induces the midline barrier by activating Nodal expression in the lateral plate. Development 2003; 130: 1795-1804.

65 Tsukui T, Capdevila J, Tamura $\mathrm{K}$ et al: Multiple left-right asymmetry defects in $\operatorname{Shh}(-/-)$ mutant mice unveil a convergence of the shh and retinoic acid pathways in the control of Lefty-1. Proc Natl Acad Sci USA 1999; 96: 11376-11381.

66 Sulik K, Dehart DB, Iangaki T et al: Morphogenesis of the murine node and notochordal plate. Dev Dyn 1994; 201: 260-278.

67 Shiratori H, Sakuma R, Watanabe M et al: Two-step regulation of left-right asymmetric expression of Pitx2: initiation by nodal signaling and maintenance by Nkx2. Mol Cell 2001; 7: 137-149.

68 Tremblay KD, Hoodless PA, Bikoff EK, Robertson EJ: Formation of the definitive endoderm in mouse is a Smad2-dependent process. Development 2000; 127: 3079-3090.

69 Liu C, Liu W, Lu MF, Brown NA, Martin JF: Regulation of leftright asymmetry by thresholds of Pitx2c activity. Development 2001; 128: 2039-2048.

70 Kioussi C, Briata P, Baek SH et al: Identification of a Wnt/Dvl/ beta-Catenin $->$ Pitx2 pathway mediating cell-type-specific proliferation during development. Cell 2002; 111: 673-685.

71 Ganga M, Espinoza HM, Cox CJ et al: PITX2 isoform-specific regulation of atrial natriuretic factor expression: synergism and repression with Nkx2.5. J Biol Chem 2003; 278: 22437-22445.

72 Horne-Badovinac S, Rebagliati M, Stainier DY: A cellular framework for gut-looping morphogenesis in zebrafish. Science 2003; 302: $662-665$.

73 Vermot J, Pourquie O: Retinoic acid coordinates somitogenesis and left-right patterning in vertebrate embryos. Nature 2005; 435: $215-220$.

74 Vermot J, Llamas JG, Fraulob V, Niederreither K, Chambon P, Dolle P: Retinoic acid controls the bilateral symmetry of somite formation in the mouse embryo. Science 2005; 308: 563-566.

75 Ansley SJ, Badano JL, Blacque OE et al: Basal body dysfunction is a likely cause of pleiotropic Bardet-Biedl syndrome. Nature 2003; 425: $628-633$. 
76 Beales PL: Lifting the lid on Pandora's box: the Bardet-Biedl syndrome. Curr Opin Genet Dev 2005; 15: 315-323.

77 Otto EA, Schermer B, Obara T et al: Mutations in INVS encoding inversin cause nephronophthisis type 2 , linking renal cystic disease to the function of primary cilia and left-right axis determination. Nat Genet 2003; 34: 413-420.

78 Ware SM, Belmont JW: ZIC3, CRC1, ACVR2B, and EBAF and the visceral heterotaxies; in Epstein C, Erickson R, Wynshaw-Boris A (eds): Inborn errors of development. Oxford: Oxford University Press, 2004, pp 300-313.

79 Aylsworth AS: Clinical aspects of defects in the determination of laterality. Am J Med Genet 2001; 101: 345-355.

80 Berg C, Geipel A, Smrcek J et al: Prenatal diagnosis of cardiosplenic syndromes: a 10-year experience. Ultrasound Obstet Gynecol 2003; 22: 451-459.

$81 \mathrm{Lin} \mathrm{JH}$, Chang CI, Wang JK et al: Intrauterine diagnosis of heterotaxy syndrome. Am Heart J 2002; 143: 1002-1008.

82 Baschat AA, Gembruch U, Knopfle G, Hansmann M: Firsttrimester fetal heart block: a marker for cardiac anomaly. Ultrasound Obstet Gynecol 1999; 14: 311-314.

83 Fesslova V, Villa L, Nava S, Boschetto C, Redaelli C, Mannarino S: Spectrum and outcome of atrioventricular septal defect in fetal life. Cardiol Young 2002; 12: 18-26.

84 Jaeggi ET, Hornberger LK, Smallhorn JF, Fouron JC: Prenatal diagnosis of complete atrioventricular block associated with structural heart disease: combined experience of two tertiary care centers and review of the literature. Ultrasound Obstet Gynecol 2005; 26: 16-21.

85 Machado MV, Tynan MJ, Curry PV, Allan LD: Fetal complete heart block. Br Heart J 1988; 60: 512-515.

86 Kispert A, Petry M, Olbrich $\mathrm{H}$ et al: Genotype-phenotype correlations in PCD patients carrying DNAH5 mutations. Thorax 2003; 58: 552-554.

87 Olbrich H, Haffner K, Kispert A et al: Mutations in DNAH5 cause primary ciliary dyskinesia and randomization of left-right asymmetry. Nat Genet 2002; 30: 143-144.

88 Omran H, Haffner K, Volkel A et al: Homozygosity mapping of a gene locus for primary ciliary dyskinesia on chromosome $5 p$ and identification of the heavy dynein chain DNAH5 as a candidate gene. Am J Respir Cell Mol Biol 2000; 23: 696-702.

89 Guichard C, Harricane MC, Lafitte JJ et al: Axonemal dynein intermediate-chain gene (DNAI1) mutations result in situs inversus and primary ciliary dyskinesia (Kartagener syndrome), Am J Hum Genet 2001; 68: 1030-1035.

90 Noone PG, Zariwala M, Sannuti A et al: Mutations in DNAI1 (IC78) cause primary ciliary dyskinesia. Chest 2002; 121: 97S.

91 Purandare SM, Ware SM, Kwan KM et al: A complex syndrome of left-right axis, central nervous system and axial skeleton defects in Zic3 mutant mice. Development 2002; 129: 2293-2302.

92 Schott JJ, Benson DW, Basson CT et al: Congenital heart disease caused by mutations in the transcription factor NKX2-5. Science 1998; 281: 108-111. 